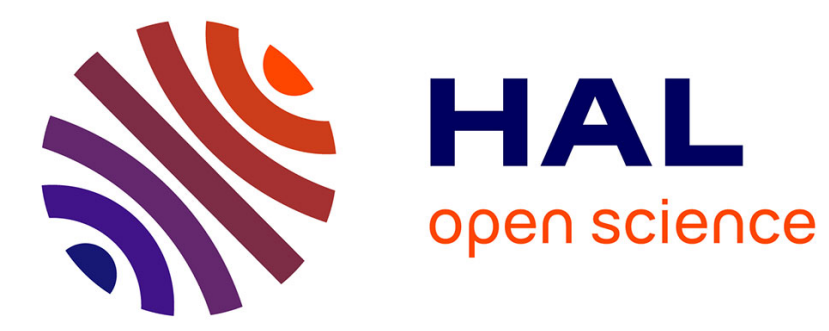

\title{
Defect investigation of excimer laser annealed silicon
}

Richard Monflier, Toshiyuki Tabata, Fuccio Cristiano, Inès Toque-Tresonne, Fulvio Mazzamuto, Julien Roul, Teresa Hungría, Corinne Routaboul, Eléna Bedel-Pereira

\section{- To cite this version:}

Richard Monflier, Toshiyuki Tabata, Fuccio Cristiano, Inès Toque-Tresonne, Fulvio Mazzamuto, et al.. Defect investigation of excimer laser annealed silicon. IEEE Nanotechnology Materials and Devices Conference, Oct 2016, Toulouse, France. hal-01343978v3

\section{HAL Id: hal-01343978 https://hal.science/hal-01343978v3}

Submitted on 12 Oct 2016

HAL is a multi-disciplinary open access archive for the deposit and dissemination of scientific research documents, whether they are published or not. The documents may come from teaching and research institutions in France or abroad, or from public or private research centers.
L'archive ouverte pluridisciplinaire HAL, est destinée au dépôt et à la diffusion de documents scientifiques de niveau recherche, publiés ou non, émanant des établissements d'enseignement et de recherche français ou étrangers, des laboratoires publics ou privés. 


\title{
Defect investigation of excimer laser annealed silicon
}

\author{
R. Monflier, T. Tabata, F. Cristiano, I. Toque-Tresonne, F. Mazzamuto, J. Roul, M.-T. Hungria- \\ Hernandez, C. Routaboul, E. Bedel-Pereira
}

\begin{abstract}
In this paper, we study the effect of excimer laser annealing on silicon and specifically the oxygen impurities induced versus laser energy density. We show that oxygen penetration from the native oxide occurs during laser annealing, which increases with increasing laser energy. At higher laser energies, oxygen precipitation occurs well below the surface, which is confirmed both by SIMS and optical spectroscopy analyses. The precipitates do not affect the dopant activation in the epitaxial layer.
\end{abstract}

\section{INTRODUCTION}

Laser annealing has been demonstrated to be an effective method to create heavily doped regions required for ultrashallow junctions, in which dopants are typically introduced by ion implantation. In this process, crystallographic defects can be completely removed by melting the surface implanted layer and allowing it to epitaxially regrow. Although no residual extended defects are generally observed by TEM analysis in such regrown material, some researchers have reported a degradation of the electrical performance of the molten areas [1-3]. Indeed, removal of the implantationinduced defects might not be complete in the recristallised zone. In particular, oxygen (O) impurity can affect the performance of devices either by thermal donor formation or by creating precipitates which act as recombination centers $[4,5]$. These defects can also be investigated by optical analysis. Indeed, optical defects known as G- and D-lines, related to $\mathrm{O}$, carbon and dislocations have been intensively studied regarding their thermal behavior, spatial distribution, and process-related modifications [6, 7]. However, some disagreements are still present among the reported works. In order to separate the contribution of the thermal process and of implantation doping to the observed defects, we have investigated in this work the formation of defects in in-situ doped epitaxial layer after melt laser annealing. The investigations were based on Secondary Ion Mass Spectrometry (SIMS), Fourier Transform Infrared (FT-IR) and micro-photoluminescence ( $\mu \mathrm{PL})$ spectroscopy, coupled with measurements of sheet resistance.

\section{EXPERIMENT}

In this study, a p-type silicon ( $\mathrm{Si}$ ) epitaxial layer of about $3 \mu \mathrm{m}$ thickness was investigated. The resistivity of the layer is $1.42 \Omega . \mathrm{cm}$, corresponding to a background doping level of $10^{16} \mathrm{~cm}^{-3}$. The doped layer was grown on a single crystal 300 $\mathrm{mm} \mathrm{Cz} \mathrm{Si} \mathrm{wafer.} \mathrm{A} \mathrm{set} \mathrm{of} 22$ zones $\left(10 \times 10 \mathrm{~mm}^{2}\right.$ size $)$ was annealed sequentially with a $\mathrm{XeCl}$ excimer laser with an energy density ranging from 1.7 to $8.0 \mathrm{~J} / \mathrm{cm}^{2}$ with a step of

R. Monflier, F. Cristiano, J. Roul, E. Bedel-Pereira are with LAAS-CNRS, Université de Toulouse, UPS, Toulouse, France.

T. Tabata, I. Toque-Tresonne, F. Mazzamuto are with SCREEN-LASSE, 14-38 Rue Alexandre, 92230 Gennevilliers, France.

M.-T. Hungria-Hernandez is with Centre de Microcaractérisation Raimond Castaing, UMS 3623, Espace Clément Ader, 3 rue Caroline Aigle, 31400 Toulouse, France.

C. Routaboul is with Institut de Chimie de Toulouse, 118 route de Narbonne, 31062 Toulouse, France.
$0.3 \mathrm{~J} / \mathrm{cm}^{2}$. Each zone received 10 laser shots with a pulse duration $\approx 160$ ns. Each wafer quarter was subjected to the same process (see Inset on Fig. 2).

\section{RESULTS}

\section{A. Roughness}

Surface roughness was first measured using a noncontact white-light interferometer. Fig. 1 shows that the roughness is less than $1 \mathrm{~nm}$ for energies up to $5 \mathrm{~J} / \mathrm{cm}^{2}$, i.e. for melt thicknesses up to $\sim 700 \mathrm{~nm}$; for higher laser energy density, the roughness constantly increases up to about $8 \mathrm{~nm}$ for an energy density of $7 \mathrm{~J} / \mathrm{cm}^{2}$ (expected melt depth: $\sim 1400 \mathrm{~nm}$ ). However, in all cases, the measured roughness remains negligible with respect to the expected melt depth (up to $\sim 5 \%$ ).

\section{B. Sheet Resistance}

Sheet resistance was measured by the four-point probe method. Fig. 2 shows sheet resistance variation with laser energy density. At high laser energies (from $5 \mathrm{~J} / \mathrm{cm}^{2}$ upwards) the sheet resistance stays constant at a value of about $1200 \Omega / \square$, which corresponds to the doping concentration of the epitaxial layer $\left(\sim 10^{16} \mathrm{~cm}^{-3}\right)$, i.e. the regrown layer is perfectly active. At lower laser energies (below $5 \mathrm{~J} / \mathrm{cm}^{2}$ ), the sheet resistance significantly increases up to about 30000 at $2.6 \mathrm{~J} / \mathrm{cm}^{2}$. In this case, the high values of sheet resistance are probably related to the presence of a high concentration of defects at the surface of the layer.

\section{Secondary Ion Mass Spectrometry}

In Fig. 3, SIMS O depth profiles are reported for energy densities in the range $0-8 \mathrm{~J} / \mathrm{cm}^{2}$ and the melt depth generated by laser represented by hatched areas for each energy density. It is evident that $\mathrm{O}$ penetration from the native oxide [8] occurs during laser annealing, and that that amount of $\mathrm{O}$ increases with energy. In addition, as shown in Fig. 3 for the highest laser energies, the penetration depth of $\mathrm{O}$ is in agreement with the thickness of the melted regions. At low laser energy, it is therefore expected that a high concentration of oxygen is present in a thin region below the surface. However, the SIMS measurement conditions used here do not allow to reliably measure this region (cf Fig. 3 where the surface peak extends to about $100 \mathrm{~nm}$ depth). This result is in qualitative agreement with the sheet resistance measurements

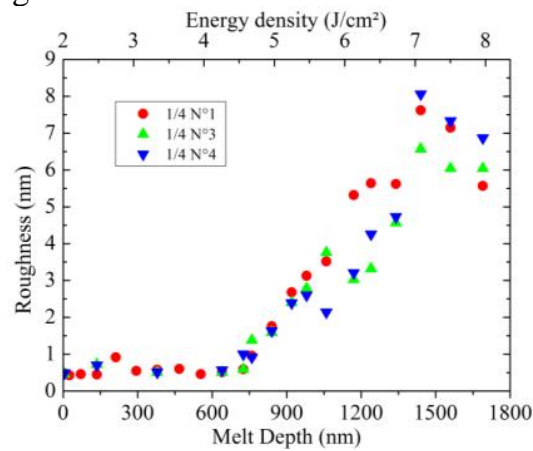

Figure 1: Evolution of roughness with melt depth and laser energy density. 


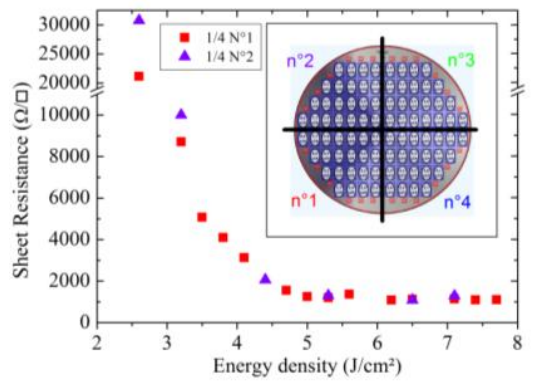

Figure 2: Evolution of sheet resistance with laser energy density. Inset: Schema of annealed zones of the 4 quarters.

concentration of oxygen-related defects might be present in the surface region, inducing a strong dopant deactivation. Finally, for highest laser energies, immobile oxygen peaks are observed, indicating that oxygen precipitation occurs at concentrations above $\sim 5 \times 10^{18} \mathrm{~cm}^{-3}$, in agreement with known values of solubility of oxygen in liquid silicon [9]. The presence of defects in the annealed samples has therefore been further investigated using optical spectroscopy methods.

\section{Optical spectroscopy measurements}

Fig. 4 shows the micro-photoluminescence ( $\mu \mathrm{PL})$ spectra obtained on various samples submitted to laser annealing in the 0.8-1.2 eV energy interval. The measured spectra are normalised with respect to the $1.07 \mathrm{eV}$ peak, related to the $\mathrm{Si}$ Band-band (Si BB) transistion. Measurement conditions are as follows: temperature equal to $70 \mathrm{~K}$, a $488 \mathrm{~nm}$ laser diode and a power of $1 \mathrm{~mW}$ for the excitation source and a $200 \mathrm{~s}$ exposure time. No Si BB peak shift is observed with increasing laser energy that evidences no change in B doping concentration. In addition, several peaks are observed in the 0.8-1.0 eV range in all annealed samples. These peaks can be associated to the presence of carbon (G-line at $0.97 \mathrm{eV}$ ) or to dislocations and/or oxygen precipitates (D-lines between 0.81 and $0.95 \mathrm{eV}$ ) [10]. In fact, the intensity of the D-lines increases with increasing laser energy, in agreement with the progressive precipitation of oxygen observed by SIMS (cf. Fig. 3). This suggests that in our case the observed D-lines are indeed a signature of the oxygen precipitation process. This conclusion is supported by Fourier Transform Infrared Spectroscopy (FTIR) analysis, showing that the intensity of the $\mathrm{Si}-\mathrm{O}$ and $\mathrm{Si}-\mathrm{O}-\mathrm{Si}$ bond-related signals regularly increase when increasing the laser energy [11]. Further work is in progress to better define the D-line spectra observed by $\mu \mathrm{PL}$ and to identify the origin of the additional signals ( $\mathrm{Si}-\mathrm{H}, \mathrm{C}-$ H) observed by FTIR.

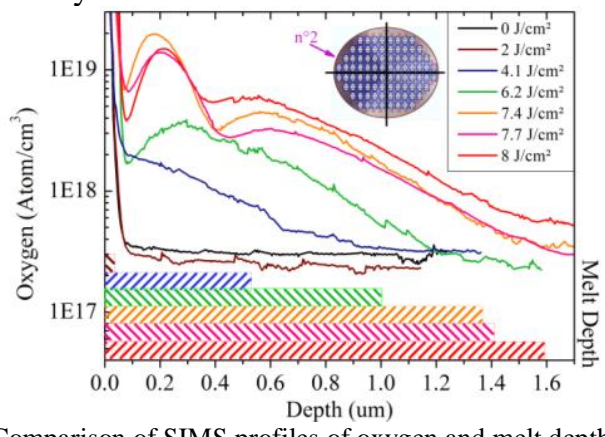

Figure 3: Comparison of SIMS profiles of oxygen and melt depth generated by laser annealing for various laser fluence.

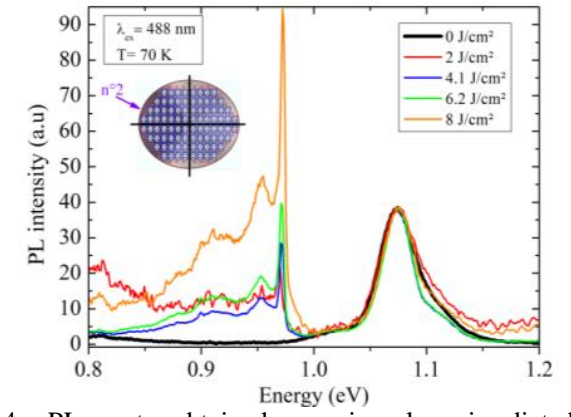

Figure 4: $\mu$ PL spectra obtained on excimer laser-irradiated zones.

\section{CONCLUSION}

In this work, we have investigated the formation of defects and the role of oxygen in in-situ doped epitaxial layers after melt laser annealing. We found that in all cases, the surface roughness measured after anneal is negligible with respect to the melt depth (less than 5\%). In addition, $\mathrm{O}$ penetration from the native oxide occurs during laser annealing, which increases with increasing laser energy. At low laser energy (below $5 \mathrm{~J} / \mathrm{cm}^{2}$ ), the oxygen concentration in the surface region is very high, which induces a strong dopant deactivation. At higher laser energies, oxygen precipitation occurs well below the surface, which is confirmed both by SIMS and optical spectroscopy analyses. The precipitates do not affect the dopant activation in the epitaxial layer, which reaches $100 \%$ at these energies.

\section{ACKNOWLEDGMENT}

This work was financially supported by the Nano2017 French programme. This work was partly supported by LAAS-CNRS micro and nanotechnologies platform member of the French RENATECH network.

\section{REFERENCES}

[1] J. L. Benton, "Electrical properties of laser annealed silicon" in $A I P$ Conference Proceedings 1979, 50, pp. 543-549.

[2] R. T. Young, "Substrate heating and emitter dopants effects in laser annealed solar cells", Applied Physics Letters 1981, 39, pp. 313-315.

[3] R. T. Young, "Laser processing for high-efficiency Si solar cells", Journal of Applied Physics 1982, 53, pp. 1178-1189.

[4] C. S. Fuller, "Effect of Heat Treatment upon the Electrical Properties of Silicon Crystals", Journal of Applied Physics. 1957, 28, 1427

[5] K. Bothe, "Electronically activated boron-oxygen-related recombination centers in crystalline silicon", Journal of Applied Physics, 2006, 99, 013701

[6] K. V. Ravi, Imperfections and Impurities in Semiconductor Silicon. Wiley, 1981.

[7] K.-Y. Shen, et. al., "Applying low-energy multipulse excimer laser annealing to improve charge retention of $\mathrm{Au}$ nanocrystals embedded MOS capacitors," Journal of Physics D: Applied Physics, vol. 48, no. 5, p. 055101, Feb. 2015.

[8] G. Impellizzeri, et. al., "Role of oxygen on the electrical activation of $\mathrm{B}$ in Ge by excimer laser annealing: Role of oxygen on the electrical activation of B in Ge," physica status solidi (a), vol. 211, no. 1, pp. 122-125, Jan. 2014.

[9] Y. Yatsurugi, et. al., "Concentration, Solubility, and Equilibrium Distribution Coefficient of Nitrogen and Oxygen in Semiconductor Silicon". J. Electrochem. Soc. 1973 120(7): 975979; doi:10.1149/1.2403610

[10] M. Tajima, "Spectroscopy and Topography of Deep-Level Luminescence in Photovoltaic Silicon," IEEE Journal of Photovoltaics, vol. 4, no. 6, pp. 1452-1458, Nov. 2014.

[11] B. Shokri, et. al., "FTIR analysis of silicon dioxide thin film deposited by metal organic-based PECVD," in Proceedings of 19th international symposium on plasma chemistry society, Bochum, Germany, 2009, vol. 2631. 